\title{
Picc and midline occlusions, nurses' knowledge: an observational study
}

\author{
Authors: Franguelli M., Ulivieri D., Ursino F., Bondielli F., Aula F., De Matteis A., Cervasio M., Cappellin M., \\ Consoli D., Agostinelli B., Capalbo S., Montagnani L.
}

\section{San Martino Polyclinic of Genoa - Liguria - Italy.}

The study evaluate nurses' knowledge about the best practices to prevent PICC and Midline occlusions, in order to set up corrective interventions.

Nurses were divided in two groups, group A included nurses who attended the refresh training about vascular access on May 2017, while group B included nurses who didn't. We used a questionnaire created by a literature review. In our Polyclinic we observed four departments. Every department has at least two similar wards, so we can compare similar patients.

During the study period occurred 37 occlusion on 377 PICC (9.81\%), and 59 occlusions on 488 Midline (12.09\%). Incidence of occlusions is similar among the units.

Incidence of PICC occlusions (9.81\%) is lower, in our Polyclinic, than the mean value obtained from other studies founded in the literature (11.32\%).

Pre-occlusion time, the time between the devices placement and its occlusion, is 42 days for PICCs and 15 days for Midlines, respectively, in medicine units, 120 and 20 days in oncology units, 81 and 40 days in hematology units, and 16 and 13 days in surgery units.

$43 \%$ of nurses from group $A$ and $35 \%$ from group $B$ gave the correct answer about the right timing of flushing. 33\% from both groups disconnect IV infusion set and syringes without clamping the devices while using neutral needle-free connectors, as the producer of the device recommends. $29 \%$ from group $A$ and $38 \%$ from group $B$ knows that drugs interactions may increase occlusion risk.
The number of correct answers $65 \%$ in group $A$ and $62 \%$ in group B) and a p-value $>0,05$ suggest that there isn't any difference in theoretical knowledge, but it's fundamental to correct the malpractices highlighted. Nurses specifically trained by the PICC Team, like the ones in oncology and hematology units, who can instruct and correct their coworkers guarantee a better management of PICCs and Midlines and longer preocclusion time. These specifically trained nurses appear to be a good solution to improve the management of the devices.

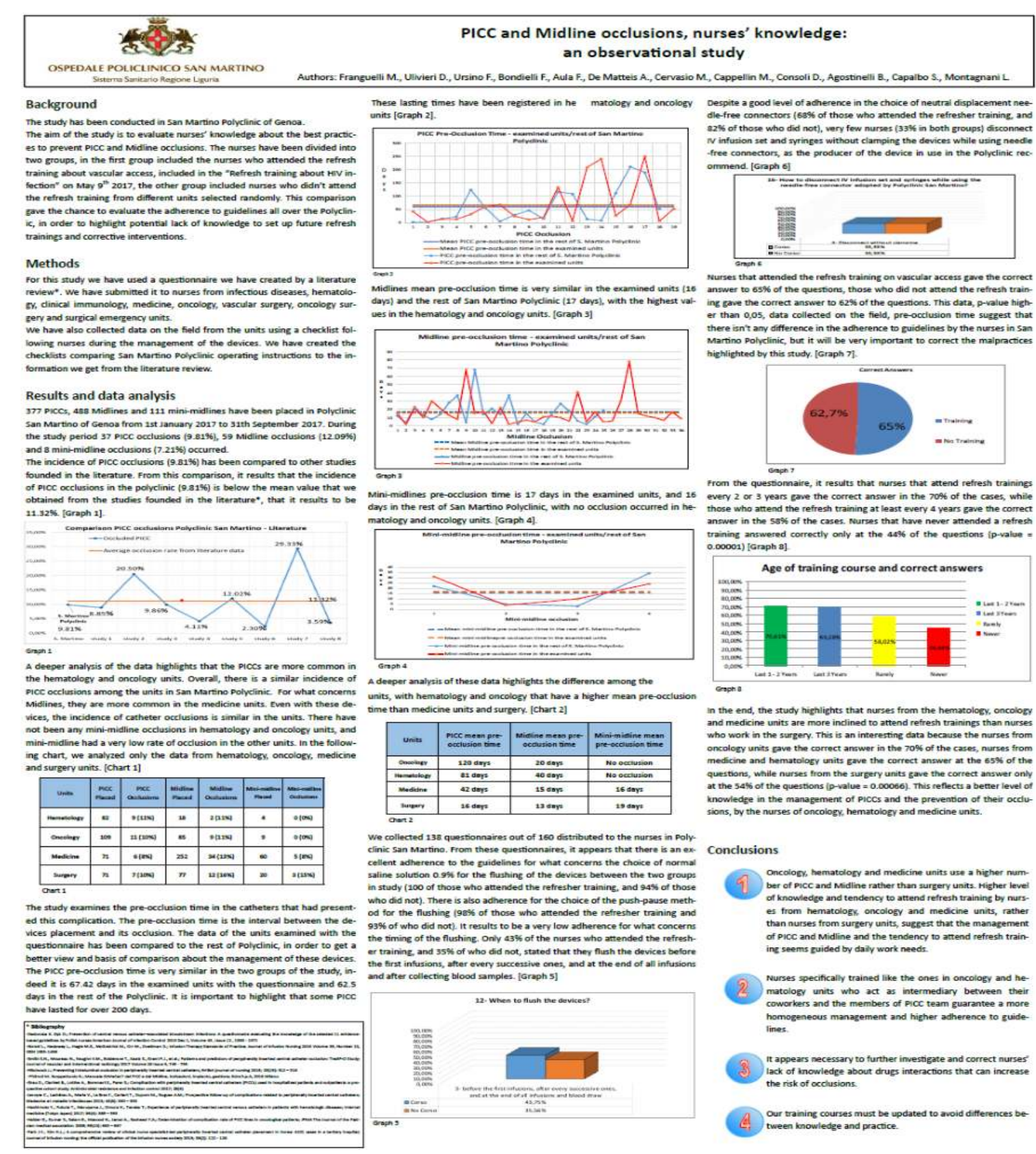

\begin{tabular}{|c|c|c|c|c|c|c|}
\hline Units & $\begin{array}{c}\text { PICC } \\
\text { Placed }\end{array}$ & $\begin{array}{c}\text { PICC } \\
\text { Occlusions }\end{array}$ & $\begin{array}{c}\text { Midlline } \\
\text { Placed }\end{array}$ & $\begin{array}{c}\text { Midline } \\
\text { Occlusions }\end{array}$ & $\begin{array}{c}\text { Mini-midline } \\
\text { Placed }\end{array}$ & $\begin{array}{c}\text { Mini-midline } \\
\text { Occlusions }\end{array}$ \\
\hline Hematology & 82 & $9(11 \%)$ & 18 & $2(11 \%)$ & 4 & $0(0 \%)$ \\
\hline Oncology & 109 & $11(10 \%)$ & 85 & $9(11 \%)$ & 9 & $0(0 \%)$ \\
\hline Medicine & 71 & $6(8 \%)$ & 252 & $34(13 \%)$ & 60 & $5(8 \%)$ \\
\hline Surgery & 71 & $7(10 \%)$ & 77 & $12(16 \%)$ & 20 & $3(15 \%)$ \\
\hline
\end{tabular}

Correct Answers

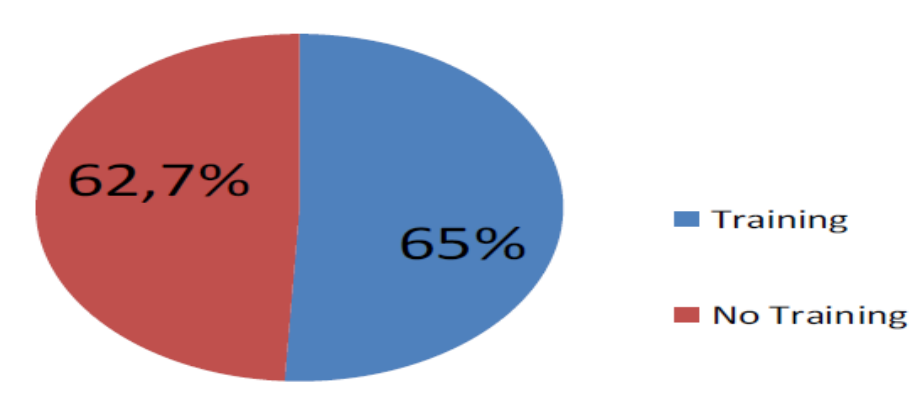

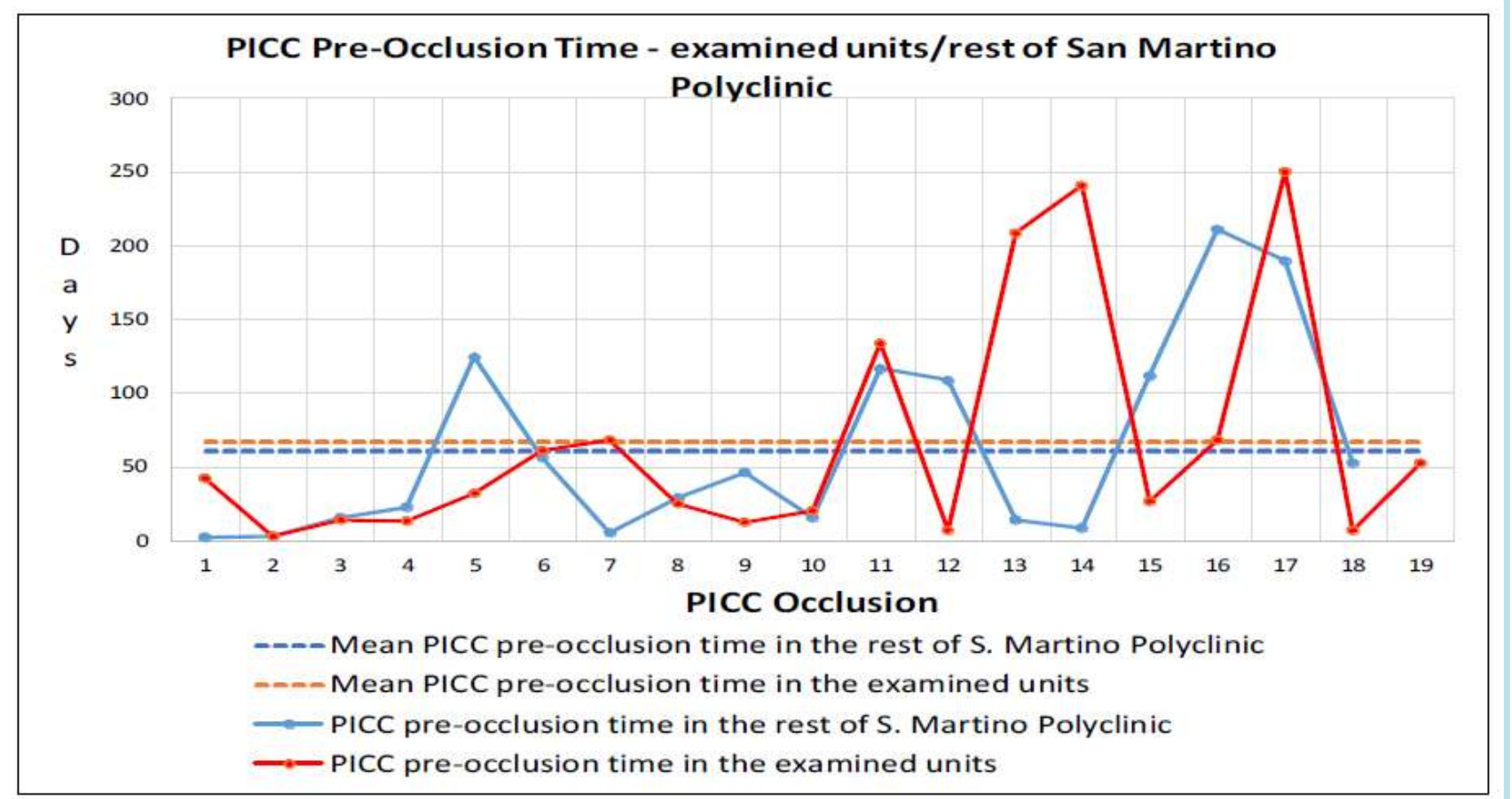

Bibliography extract

-Dedunska K. Dyk D.; Prevention of central venous catheter-associated bloodstream infections: A questionnaire evaluating the knowledge of the selected 11 evidencebased guidelines by Polish nurses American Journal of Infection Control 2015 Dec 1, Volume 43, Issue 12, 1368 - 1371

-Gorski L., Hadaway L., Hagle M.E., McGoldrick M., Orr M., Doellman D.; Infusion Therapy Standards of Practice; Journal of Infusion Nursing 2016 Volume 39, Number 1S, ISSN 1533-1458

-Smith S.N., Moureau N., Vaughn V.M., Boldenow T., Kaatz S., Grant P.J., et al.; Patterns and predictors of perypherally inserted central catheter occlusion: The3P-O Study; Journal of vascular and interventional radiology 2017 Volume 28 Issue 5, 749 - 756

-Hitchcock J.; Preventing intraluminal occlusion in peripherally inserted central catheters; British journal of nursing 2016; 25(19): S12-S18 - Pittiruti M. Scoppettuolo G.; Manuale GAVeCeLT dei PICC e dei Midline, indicazioni, impianto, gestione; Edra S.p.A, 2016 Milano 